\title{
TECNOLOGÍA EN ELECTRÓNICA
}

Título: Tecnólogo (a) en Electrónica Jornada: Diurna, nocturna Código SNIES: 28296210381100111201

Modalidad: Presencial

\begin{tabular}{|c|c|c|}
\hline Estudiante & Asesor & Tituto Trabajo de Grado \\
\hline $\begin{array}{l}\text { Diego Aragonés } \\
\text { Víctor Gasca }\end{array}$ & Santiago Salazar & $\begin{array}{l}\text { Diseño e implementación de una } \\
\text { máquina para la perforación de } \\
\text { circuitos impresos }\end{array}$ \\
\hline $\begin{array}{l}\text { Carolina Gómez } \\
\text { Marcela Muñoz } \\
\text { Juan Urriaga }\end{array}$ & Diego Cano & $\begin{array}{l}\text { Diseño e implementación de una } \\
\text { máquina para el empacado de } \\
\text { dulces }\end{array}$ \\
\hline Jhon Suárez & Diego Cano & $\begin{array}{l}\text { Diseño e implementación de una } \\
\text { planta piloto para el control de tem- } \\
\text { peratura - Posición }\end{array}$ \\
\hline Jovier Pérez & Diego Cano & $\begin{array}{l}\text { Diseño e implementación de una } \\
\text { planta piloto para el control de nivel }\end{array}$ \\
\hline $\begin{array}{l}\text { Alejandro Cedeño } \\
\text { Andrés Alzate }\end{array}$ & William Rey & $\begin{array}{l}\text { Diseño e implementación de una } \\
\text { interfaz multitouch }\end{array}$ \\
\hline Felipe Medina & Diana Lancheros & $\begin{array}{l}\text { Diseño e implementación de un } \\
\text { control de posición para la banda } \\
\text { transportadora de la célula de } \\
\text { manufactura }\end{array}$ \\
\hline Federico Molina & Diana Lancheros & $\begin{array}{l}\text { Diseño e implementación de una } \\
\text { máquina para la medición de cable }\end{array}$ \\
\hline $\begin{array}{l}\text { Javier Ruiz } \\
\text { Evelyn Pilar Díaz }\end{array}$ & Carlos Giraldo & $\begin{array}{l}\text { Diseño e Implementación de un } \\
\text { controlador desde celular basado } \\
\text { en tecnología bluetooth para un } \\
\text { automóvil a escala }\end{array}$ \\
\hline $\begin{array}{l}\text { Carlos Elmouallem } \\
\text { Pedro Torres } \\
\text { Jhonathan Páez }\end{array}$ & $\begin{array}{l}\text { Viviana Garzón } \\
\text { Iván García }\end{array}$ & $\begin{array}{l}\text { Diseño e implementación de un } \\
\text { sistema para el control de } \\
\text { temperatura en el horneado de } \\
\text { masa para arepas }\end{array}$ \\
\hline $\begin{array}{l}\text { Wilson Escobar } \\
\text { Giovanni Vargas }\end{array}$ & Jhon William Vasquez & $\begin{array}{l}\text { Diseño e implementación de un } \\
\text { sistema de moldeo para la } \\
\text { fabricación de arepas }\end{array}$ \\
\hline Cristian Solórzano & Jhon William Vasquez & $\begin{array}{l}\text { Automatización de un sistema de } \\
\text { envasado para FUNDASES }\end{array}$ \\
\hline
\end{tabular}

